\title{
Correction to "Mediating the Migration of Mesenchymal Stem Cells by Dynamically Changing the Density of Cell-selective Peptides Immobilized on $\beta$-Cyclodextrin-modified Cell-resisting Polymer Brushes"
}

Wang Du, De-Teng Zhang, Xue-Mei Wang, Tan-Chen Ren, and Chang-You Gao*

Ministry of Education Key Laboratory of Macromolecular Synthesis and Functionalization, Department of Polymer Science and Engineering, Zhejiang University, Hangzhou 310027, China

Citation: Du, W.; Zhang, D. T.; Wang, X. M.; Ren, T. C.; Gao, C. Y. Correction to "Mediating the migration of mesenchymal stem cells by dynamically changing the density of cell-selective peptides immobilized on $\beta$-cyclodextrin-modified cell-resisting polymer brushes". Chinese J. Polym. Sci. 2020, 38, 1045-1046.

The authors regret that Fig. 4(c) was misplaced by the first author originally. The corrected version of Fig. 4 is provided below. The quantitative analysis shown in Fig. 4(b) is not changed, and thus the conclusions related to Fig. 4 and reported in this article are not altered. Additional text corrections are not needed. The authors apologize for any inconvenience caused.

*Corresponding author, E-mail: cygao@zju.edu.cn 

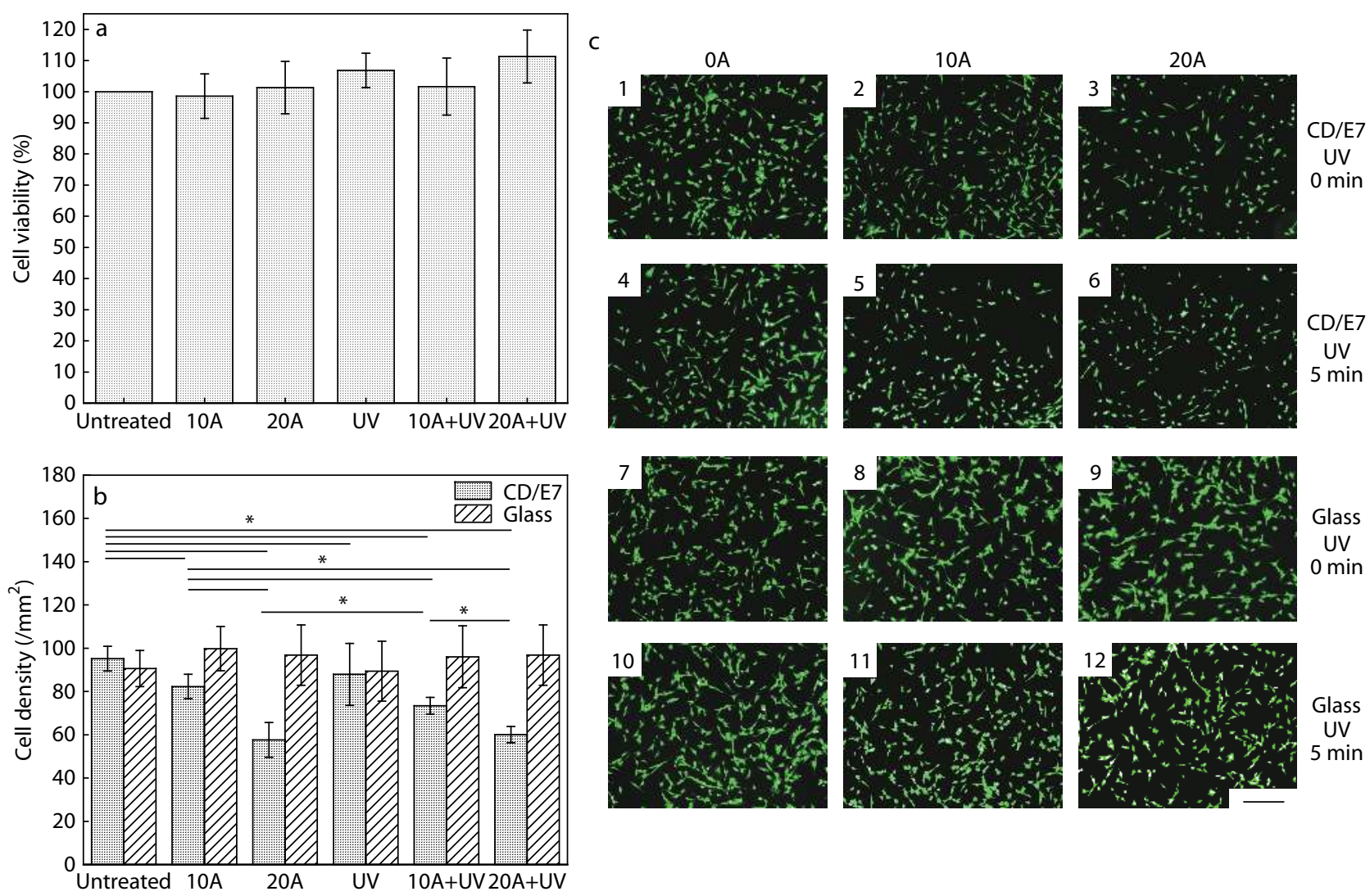

Fig. 4 (a) Viability of BMSCs on TCPS after being treated with different methods; (b) Density of BMSCs on CD/E7 surface after various stimulations. BMSCs were seeded at a density of $10^{4}$ cells $/ \mathrm{cm}^{2}$ and incubated for $4 \mathrm{~h}$, followed by adding certain amount of Ama and/or irradiation with UV light. The cells were then incubated for another $2 \mathrm{~h}$ before the medium was exchanged with a new one; $12 \mathrm{~h}$ later, the cells were imaged and the cell numbers were statistically quantified. $10 \mathrm{~A}$ and $20 \mathrm{~A}$ represent treatment with $10 \mu \mathrm{mol} / \mathrm{L}$ Ama and $20 \mu \mathrm{mol} / \mathrm{L}$ Ama, respectively. UV, 10A+UV, and 20A+UV represent UV irradiation for $5 \mathrm{~min}$, and with $10 \mu \mathrm{mol} / \mathrm{L}$ Ama and $20 \mu \mathrm{mol} / \mathrm{L}$ Ama treatment, respectively. At least 10 images were analyzed for each data point, and 3 independent experiments were carried out. ${ }^{*}$ ) indicates a significant difference at $p<0.05$; (c) FDA staining images of BMSCs on (1-6) CD/E7 and (7-12) glass surfaces after various stimulations corresponding to the quantitative data of Fig. 4(b) (1, 7: Untreated; 2, 8: 10A; 3, 9:20A; 4, 10: UV; 5, 11: 10A+UV; 6, 12: 20A+UV). Scale bar $=20 \mu \mathrm{m}$. 